\title{
Mid-term follow-up results after implementing a new strategy for the diagnosis and management of periprosthetic joint infections
}

Rares Mircea Birlutiu ${ }^{1 *}$, Manuela Mihalache ${ }^{1}$, Patricia Mihalache ${ }^{2}$, Razvan Silviu Cismasiu 3,4 and Victoria Birlutiu ${ }^{1,5}$

\begin{abstract}
Background: Periprosthetic joint infections (PJIs) represent one of the most serious complications associated with joint replacement surgeries, a complication also of modern orthopedic surgery despite the efforts that occurred in this field. Frequently PJls lead to prolonged morbidity, increased costs and mortality.

Methods: We are conducting a single-center observational cohort ongoing study in the Academic Emergency Hospital Sibiu, Romania, study in which sonication of the retrieved and as a rapid method of bacteria detection, molecular identification of bacteria by $16 \mathrm{~S}$ rRNA beacon-based fluorescent in situ hybridization (bbFISH) are used.

Results: A total of 61 patients were enrolled in this study. The diagnosis of aseptic loosening was established in 30 cases (49.1\%) and the diagnosis of periprosthetic joint infection was established at 31 patients (50.8\%). The mean follow-up period in the subgroup of patients diagnosed with periprosthetic joint infections was $36.06 \pm 12.59$ months (range: 1-54). The 25-months Kaplan-Meier survival rate as the end point, as a consequence of the period of enrollment and a different follow-up period for each type of surgical procedure, was $75 \%$ after debridement and implant retention, $91.7 \%$ after one-stage exchange, 92.3\% after two-stage exchange, and 100\% after three-stage exchange. There were no significant differences in survival percentage.

Conclusions: Our study has good results similar to previously published data. We cannot recommend one strategy of managing prosthetic joint infections over the other. Definitely, there is a need for prospective randomized controlled trials.
\end{abstract}

Keywords: Periprosthetic joint infection, Sonication, Surgical management, Biofilm, Mid-term follow-up results

\section{Background}

Although Anthony van Leeuwenhoek (1632-1723), observes and describes the bacterial biofilm by using a rudimentary microscope analyzing specimens of tissue from his oral cavity, on which he highlights the presence of aggregates of microbes in the "scurf of the teeth" and

\footnotetext{
*Correspondence: raresmircea@gmail.com

'Lucian Blaga University of Sibiu, Faculty of Medicine Sibiu, Str. Lucian Blaga, Nr. 2A, 550169 Sibiu, Romania

Full list of author information is available at the end of the article
}

from "particles scraped off his tongue" between 1683 and 1708 , accelerated research on the study of the biofilm only began to make important discoveries in the last $20-25$ years [1]. Unofficially the total annual cost of the management of biofilm-related infections in the United States is around \$94 billion and more than half a million deaths are associated with this economic burden. A United States Centers for Disease Control and Prevention report from 2007 is estimated that in the US alone 1.7 million hospital-acquired infections annually are

C C The Author(s). 2021 Open Access This article is licensed under a Creative Commons Attribution 4.0 International License, which permits use, sharing, adaptation, distribution and reproduction in any medium or format, as long as you give appropriate credit to the original author(s) and the source, provide a link to the Creative Commons licence, and indicate if changes were made. The images or other third party material in this article are included in the article's Creative Commons licence, unless indicated otherwise in a credit line to the material. If material is not included in the article's Creative Commons licence and your intended use is not permitted by statutory regulation or exceeds the permitted use, you will need to obtain permission directly from the copyright holder. To view a copy of this licence, visit http://creativecommons.org/licenses/by/4.0/ The Creative Commons Public Domain Dedication waiver (http://creativecommons.org/publicdomain/zero/1.0/) applies to the data made available in this article, unless otherwise stated in a credit line to the data. 
biofilm-related infections, requiring an additional $\$ 11$ billion in healthcare costs for the management of these patients $[2,3]$. Dental caries and periodontitis are the most prevalent biofilm-related infections requiring in the United States alone \$105 billion on dental care [4]. The spectrum of biofilm-related infections is comprehensive, from catheter-associated urinary tract infections that are the most common device-related biofilm infections to central line-related blood stream infections, periprosthetic joint infections, biofilm-related infection associated with the presence of fixed braces [5, 6] and ventilator-associated pneumonia are also of important concern [7]. Periprosthetic joint infections and catheter-associated urinary tract infections are, probably, the two most important biofilm-related foreign body infections, associating a great economic impact in health care [2]. The ESKAPE group of pathogen contains highly virulent and antibiotic resistant bacterial pathogens, most of these strains being biofilm-producers. Strains that pose a significant interest in studying the possible relationship between the biofilm-producer phenotype and their MDR status. Several studies have been published and provide data on this relationship, data from both MDR and wild-type strains (eg, Escherichia coli or MSSA/ MRSA). The conclusions of these studies currently available data are frequently controversial $[8,9]$.

Periprosthetic joint infections (PJIs) are one of the most serious complications associated with joint replacement surgeries [10], a complication also of the modern orthopedic surgery despite the efforts that occurred in this field. Frequently PJIs lead to prolonged morbidity, increased costs and mortality [11, 12]. PJIs continue to develop in increasing numbers despite all the international efforts, the rate of PJI is estimated to range between 0.5 and $2.4 \%$ after primary total hip and knee arthroplasties, and up to $20 \%$ in cases of revision surgeries $[13,14]$. An accurate diagnosis of PJIs is crucial for treatment outcome especially having in mind the fact that the management of aseptic loosening is different from the one of PJIs. The management of PJIs remains a difficult one.

In this setting, the beginning of September 2016 was an important key point in time for the Academic Emergency Hospital Sibiu, Romania when a new strategy for the diagnosis and management of the periprosthetic joint infections was adopted and implemented, a strategy that uses sonication of the retrieved and as a rapid method of bacteria detection, a molecular identification of bacteria by $16 \mathrm{~S}$ rRNA bbFISH (beacon-based fluorescent in situ hybridization) technology using a bbFISH kit (hemoFISH Masterpanel, miacom diagnostics $\mathrm{GmbH}$ Düsseldorf, Germany).

\section{Materials and methods}

\section{Study design}

We are conducting a single-center observational cohort ongoing study in the Academic Emergency Hospital Sibiu, Romania, a county hospital with 1054 beds. Before patient inclusion in the study, the study protocol was reviewed and an approval from the institutional review board was received. A standardized diagnostic system was used for all patients that underwent a surgical intervention of revision of a joint prosthesis, to assess the implant failure. Our new implemented diagnostic and management strategy included a standardized sampling of at least 4 intraoperative tissue samples ( 1 of the samples being used for the histopathological examination (periperiprosthetic membrane) and the other are sent to the microbiological laboratory for bacterial cultures), sonication of retrieved orthopedic implants (periprosthetic components or polymethylmethacrylate (PMMA) spacer) and harvesting of the sonication fluid, a complex analysis of the synovial fluid, and also a state of the art assessment of the sonication fluid using a bbFISH kit (hemoFISH Masterpanel, Miacom diagnostics $\mathrm{GmbH}$ Düsseldorf, Germany) as a rapid method of bacteria detection (an assay that combines the well-known classical FISH technology with the usage of fluorescently labelled DNA-molecular beacons as probes). All biological sample that required cultures were inoculated and incubated aerobically, anaerobically and in high concentration of $\mathrm{CO}_{2}$ (GENbag-GENbox Atmospheric generators bioM rieux, Marcy-l'Étoile, France) at $37^{\circ} \mathrm{C}$. Isolated bacteria are identified using the VITEK 2 Compact analyzer (bioMérieux, Marcy-l'Étoile, France). The minimum inhibitory concentrations are assessed according to the European Committee on Antimicrobial Susceptibility Testing breakpoints. Synovial fluid was analyzed for cellularity, C-reactive protein levels, and leukocyte esterase. Also, a 14-day period of incubation was implemented. The full details of the implemented protocol were published in some of our previous articles $[15,16]$.

\section{Study population}

We prospectively included in this study all consecutive patients aged over 18 years, that were hospitalized from September 2016 through January 2019, patients that underwent a joint arthroplasty revision surgery for any reason. Detailed information regarding the enrolled subjects was abstracted from the medical records. We evaluated the retrieved information for the following data: demographic characteristics; clinical, radiographic, laboratory, histopathological, and microbiological data; type of surgical management, and antimicrobial management. Complete data were available for all the participants in the study. The enrolled patients were followed until they develop a treatment failure, died, or were lost 
during the follow-up period. The follow-up period was extended until April 2021, with the study population being followed for a maximum period of 55 months. The data were statistically analyzed using IBM SPSS Statistics $^{\oplus}$ version 26 software. The level of statistical significance was set at $p<0.05$. Kaplan-Meier survival curves are widely used in clinical and fundamental research. The Kaplan-Meier estimator, or Kaplan-Meier estimation function, is used to estimate the survival function or survival rate. The visual representation of this function is usually called the Kaplan-Meier curve and shows the probability of an event (for example, survival) at a certain point in time. If the sample size is large enough, the curve should approach the true survival rate of the research population. These curves are usually generated to assess the survival rate of patients at different statistical intervals such as the 30 days survival rate. To generate Kaplan - Meier curves in the therapeutic management of patients diagnosed with periprosthetic joint infections, we used the Kaplan - Meier survival function of the IBM SPSS Statistics ${ }^{\circ}$ version 26 software. Since no death events were recorded in this research, we defined the survival rate by the absence rate of infection and mortality by the recurrence rate of the infection.

\section{Study definitions and classification}

Periprosthetic joint infection was defined using the criteria from the workgroup of the Musculoskeletal Infection Society published by Javad Parvizi et al. [17] We used the classification proposed by Zimmerli et al. to determine if there is an acute, late chronic, or acute late periprosthetic joint infection, a classification that defines the prosthetic joint infections as early (occurring within 3 months after surgery), delayed (3-24 months) and late (>24 months) [18]. We also used a much simpler classification, a classification from the Pocket Guide to Diagnosis \& Treatment of Periprosthetic Joint Infection (PJI) of the PRO-IMPLANT Foundation, Berlin, Germania (coordinated by N. Renz and A. Trampuz) a guide that is in line with national and international recommendations and that defines periprosthetic infections as acute or chronic (Perioperative/Hematogenous or per continuitatem).

\section{Results}

A total of 61 patients were enrolled in this study during the analyzed period, representing a total number of 61 retrieved implants, eighter endoprosthesis $(n=58)$, or PMMA spacers $(n=3)$. The diagnosis of aseptic loosening of an endoprosthetic implant was established in 30 cases $(49.1 \%)$ and the diagnosis of periprosthetic joint infection was established at 31 patients $(50.8 \%)$. Thus, in 2016, 14 patients were enrolled (23\%), 7 of them being diagnosed with aseptic loosening and the rest with periprosthetic joint infection. In 2017, 19 patients were enrolled (31.1\%), 13 patients belonging to the study group with patients diagnosed with aseptic loosening, and 6 patients diagnosed with a periprosthetic joint infection. In 2018, 17 patients were enrolled (27.9\%), 8 patients were diagnosed with aseptic loosening and 9 patients diagnosed with a periprosthetic joint infection, and in 201911 patients were enrolled (18\%), 2 patients belonging to the study group with patients diagnosed with aseptic loosening and 9 patients diagnosed with a periprosthetic joint infection. There were no statistically significant differences between the 2 study groups in terms of the patient enrollment period $(p=0.690)$. Of the 30 retrieved implants from the 30 patients diagnosed with aseptic loosening of an endoprosthetic implant, 16 of them were hip and 14 knee implants, and in the group of patients diagnosed with a periprosthetic infection, 14 hip implants, 14 knee implants, and 3 PMMA preformed hip spacers. Regarding the PMMA spacers, the initial surgeries (the first stage of a two-stage revision surgery) were performed before the introduction of the proposed diagnostic strategy and no pathogen was isolated. Overall $(n=61)$ the mean age of the studied population was $67.62 \pm 8.058$ years (range: $44-83$ years). In the subgroup of patients diagnosed with aseptic loosening, the mean age of the patients was 68.50 years (range, 44-83 years, standard deviation \pm 8.768 ). In the subgroup of patients diagnosed with a periprosthetic joint infection, the mean age of the patients was $68 \pm$ 7.422 years (range: $49-83$ years). Twenty-nine patients were male patients $(47.5 \%)$ and 32 patients were living in rural areas in the entire study group. Twentytwo patients were female patients $(73.3 \%)$ and 17 patients were living in rural areas (56.6\%) in the subgroup of patients diagnosed with aseptic loosening and in the subgroup of patients diagnosed with a periprosthetic joint infection, 10 patients were female patients (32.2\%) and 15 patients were living in rural areas $(48.3 \%)$. There were no statistically significant differences between the 2 study groups related to age or background of the patients, $p=0.574$, respectively $p=0.517$. From the gender point of view, there were statistically significant differences between the 2 subgroups, $p=0.001$.

Using the classification proposed by Zimmerli et al., we were able to group the 31 patients diagnosed with periprosthetic joint infection as follows: 9 patients diagnosed with early periprosthetic joint infection, 6 patients with delayed periprosthetic joint infection and 16 patients were diagnosed with a late periprosthetic joint infection.

Using the classification of the periprosthetic joint infections proposed in the Pocket Guide by the PRO- 
IMPLANT Foundation, 5 patients were diagnosed with an acute perioperative infection, 4 patients with acute hematogenous infection, and 22 patients with chronic prosthetic joint infection. The number of patients diagnosed with an acute periprosthetic joint infection in 2016 was 2, in 2017 1, in 2018 1, and 2 cases in 2019. Patients diagnosed with a hematogenous acute periprosthetic joint infection in 2016 were 0, in 2017 1, in 2018 0, and in 20192 cases. Regarding the patients diagnosed with a chronic periprosthetic joint infection in 2016, there were 0 cases, in 2017 4, in 2018 8, and 5 patients had been diagnosed in 2019 .

We analyzed all 31 cases of periprosthetic joint infections from a therapeutic management point of view. Surgical management was associated with specific antibiotic therapy in all cases. None of the enrolled patients were managed with long-term suppressive antibiotic therapy (Table 1.)

The implemented therapeutic strategy failed in two cases.

Patients were followed up and evaluated postoperatively until they developed treatment failure, died, or were lost during the follow-up period. During the study period from the available documents no patient died, and no patient was lost during study.

The mean follow-up period in patients diagnosed with aseptic loosening of an endoprosthetic implant was $42.73 \pm 8.835$ months (range: 26-54) with a standard error of 1.613 months, and a 95\% Confidence Interval for Mean with a lower bound of 39.43 months and an upper bound of 46.03 months.

The mean follow-up period in the subgroup of patients diagnosed with periprosthetic joint infections was $36.06 \pm 12.596$ months (range: 1-54) with a standard error of 2.262 months, and a 95\% Confidence Interval for Mean with a lower bound of 31.44 months and an upper bound of 40.68 months.

Kaplan-Meier survival analysis of the study group $(n=61)$ Analyzing the cumulative survival table, the cumulative probability of mortality at 30 days is $1.6 \%$, at 25 months $3.3 \%$, and at 54 months $3.3 \%$ or the cumulative probability of survival at 30 days is $98.4 \%$, at 25 months $96.7 \%$, and at 54 months $96.7 \%$. (Fig. 1).

\section{Kaplan-Meier survival analysis on study subgroups}

We performed this analysis on the two study groups. Again, after assessing the cumulative survival table, the cumulative probability of mortality in patients diagnosed with aseptic loosening of the implant, at 12 months $0 \%$, and at 54 months $0 \%$ or the cumulative probability of survival at 12 months $100 \%$, and at 54 months $100 \%$. Regarding the patients diagnosed with periprosthetic joint infection the cumulative probability of mortality at 1 month $3.2 \%$, at 25 months $4.4 \%$, and at 54 months $4.4 \%$ or the cumulative probability of survival at 1 month is $96.8 \%$, at 25 months $93.5 \%$, and at 54 months $93.5 \%$. (Fig. 2).

As several surgical procedures have been used in the subgroup of patients diagnosed with a periprosthetic joint infection, an analysis according to them is also necessary.

\section{Kaplan-Meier survival analysis of the PJls subgroups by type of surgical procedure}

As previously mentioned, the therapeutic management implemented failed in two cases. In the first case, the failure was caused by a lack of compliance with the antibiotic regimen (the patient interrupted the ciprofloxacin therapy at home after 30 days), in the context of an immunocompromised patient that was on immunosuppressive therapy for a kidney transplant. As a method of treatment, a resection arthroplasty was performed - a Girdlestone procedure, being a case of failed treatment for a recurrent infection associated with a total hip arthroplasty. At 54 months of follow-up since the last surgery, there are no signs of reinfection. In the second case, a periprosthetic joint infection caused by a bacterial strain of Enterococcus faecalis (at 25 months after the revision surgery, the patient returns for pain-like complaints in the hip, associated with a fistula; a two-stage exchange procedure was performed). The patient is free of infection at the last fallow-up (Table 2.)

For this analysis, we will report the data for a period of 25 months of follow-up (as a consequence of the period of enrollment and a different follow-up period for each type of surgical procedure), and in Fig. 3 is the survival function (estimation that is limited to the largest survival time) (Fig. 3, Table 3).

Table 1 Distribution of the number and the type of surgeries by type of periprosthetic joint infections

\begin{tabular}{llll}
\hline Surgical intervention & \multicolumn{2}{l}{ Type of periprosthetic joint infection } \\
\cline { 2 - 4 } & Acute & Acute hematogenous & Chronic \\
\hline 3SE - Three-stage exchange & - & - & 1 \\
TSE - Two-stage exchange & 1 & 1 & 12 \\
OSE - One-stage exchange & 2 & 3 & 9 \\
DAIR - Debridement and implant retention & 2 & - \\
\hline
\end{tabular}




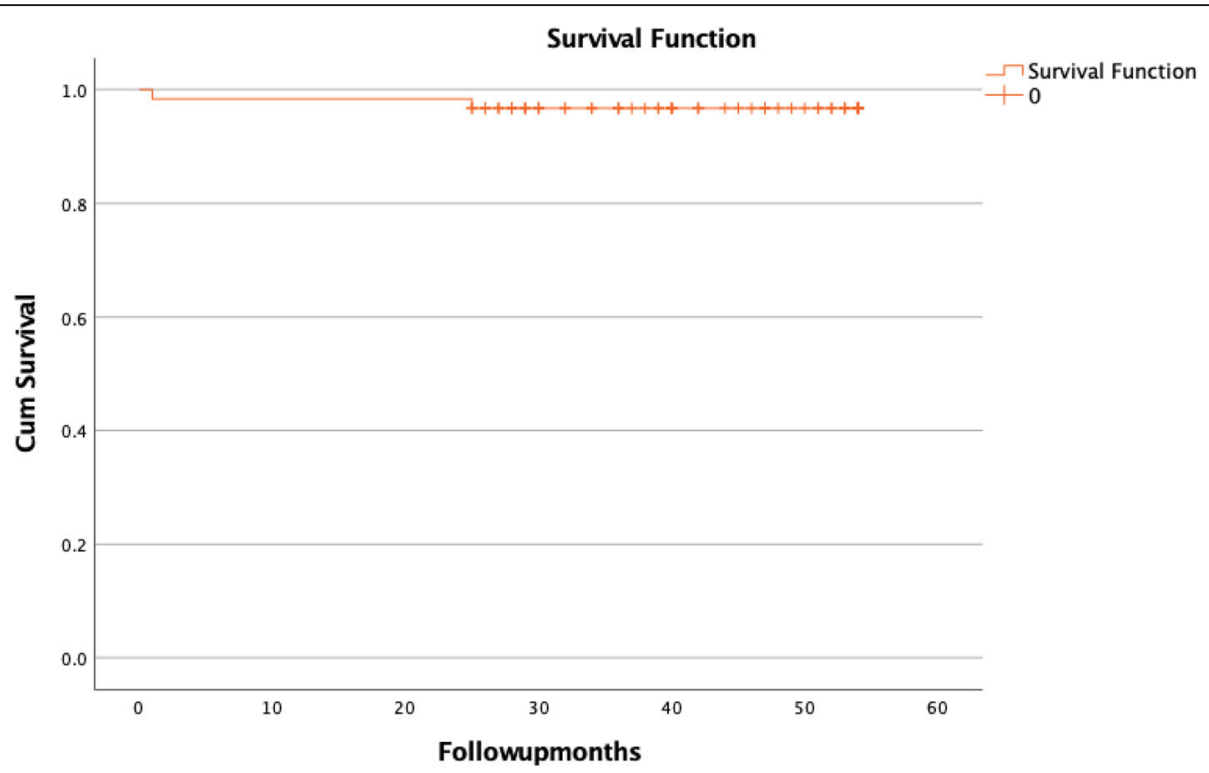

Fig. 1 Kaplan-Meier survival plot of the study group $(n=61)$

\section{Discussion}

The diagnosis and management of periprosthetic joint infections remain an issue. The adapted protocols of the management of biofilm-related infections and new diagnostic methods have improved the rate of eradication, without having a $100 \%$ certainty that the infections have been eradicated. Well-equipped treatment centers for diagnosis and multidisciplinary teams of surgeonsinfectious disease specialists - clinical microbiologists are needed. Periprosthetic joint infections are the most feared complication associated with joint arthroplasty and require an early, rapid, and accurate diagnosis, that can lead to the implementation of an adapted therapeutic management strategy. PJIs are complications that are associated with increased length of hospitalization, frequent readmissions and surgeries, an increased cost of management, and increased morbidity and mortality $[3,14,19]$.

During our follow-up period, based on the two cases of treatment failure associated with a two-stage

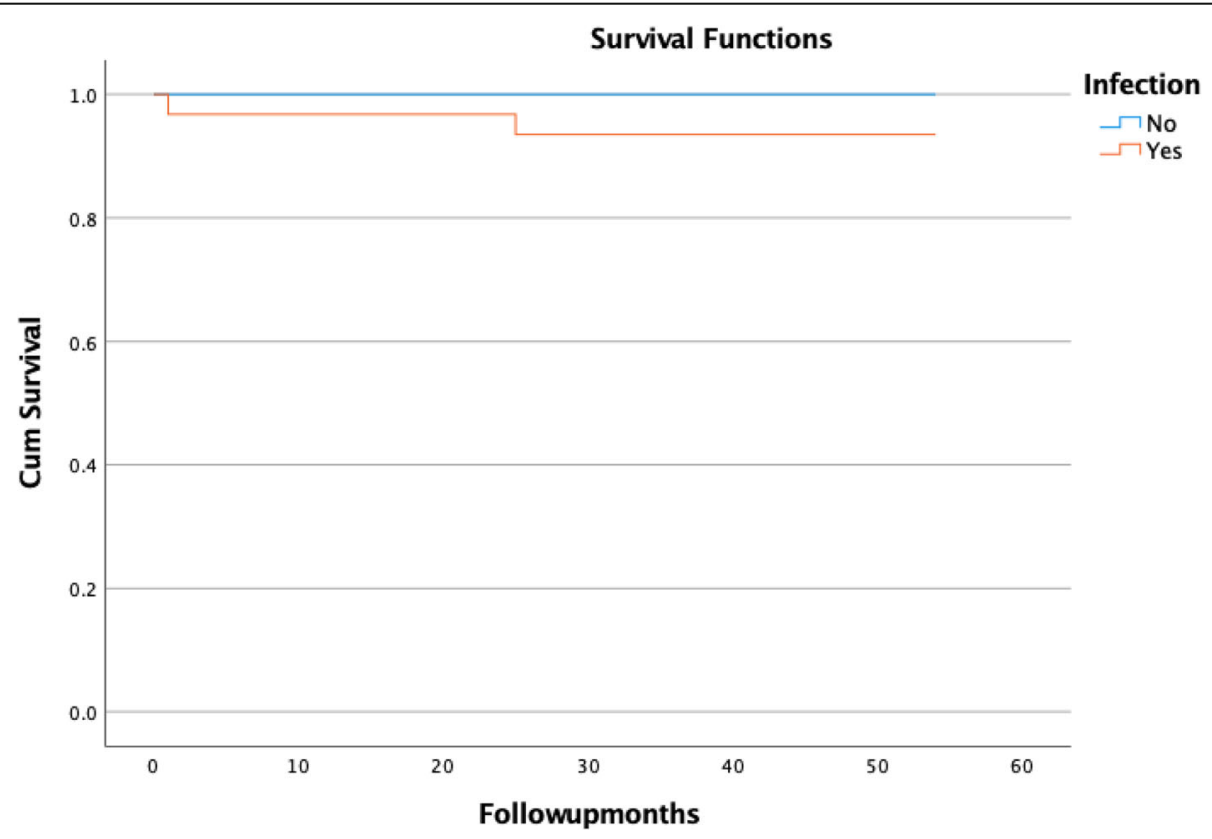

Fig. 2 Kaplan-Meier survival plot of the study group by infection 
Table 2 Follow-up period by type of surgical management

\begin{tabular}{|c|c|c|c|c|c|}
\hline \multirow[t]{2}{*}{ Statistic } & & \multicolumn{4}{|l|}{ Surgery } \\
\hline & & Aseptic Loosening Intervention & DAIR & OSE & TSE \\
\hline Mean & & 42.73 & 28.25 & 38.50 & 35.21 \\
\hline \multirow[t]{2}{*}{ 95\% Confidence Interval for Mean } & Lower Bound & 39.43 & 26.25 & 32.39 & 26.13 \\
\hline & Upper Bound & 46.03 & 30.25 & 44.61 & 44.30 \\
\hline 5\% Trimmed Mean & & 43.02 & 28.22 & 38.39 & 36.07 \\
\hline Median & & 43.00 & 28.00 & 39.00 & 29.50 \\
\hline Variance & & 78.064 & 1.583 & 92.455 & 247.566 \\
\hline Std. Deviation & & 8.835 & 1.258 & 9.615 & 15.734 \\
\hline Minimum & & 26 & 27 & 25 & 1 \\
\hline Maximum & & 54 & 30 & 54 & 54 \\
\hline Range & & 28 & 3 & 29 & 53 \\
\hline
\end{tabular}

*Follow-up months is constant when Surgery $=3$ SE. Data has been omitted

exchange intervention, we can state that, in the case of this group of studied patients, the recurrence rate of a periprosthetic joint infection is $6.45 \%$.

The 25-months Kaplan-Meier survival rate as the end point, as a consequence of the period of enrollment and a different follow-up period for each type of surgical procedure, was $75 \%$ after debridement and implant retention, $91.7 \%$ after one-stage exchange, 92.3\% after two-stage exchange, and $100 \%$ after three-stage exchange. There were no significant differences in survival percentage. No significant difference in survival rate between patients that underwent a one-stage or two-stage exchange was also published in previous studies [20-26]. Success rates associated with a debridement and implant retention strategy published in the last 20-years are between 31 and $82 \%$ depending on the involved pathogen [27-34]. Buchholz et al. published in 1981 a large study reporting a success rate of $77 \%$ for a periprosthetic joint infection associated with hip arthroplasty [35]. Other studies reported success rates between 84 and 100\% [36-39]. Two-stage exchange arthroplasty is generally an effective strategy for the management of periprosthetic joint infection, with success rates reported in the case of hip PJI between 87 and 100\% [40-42] Studies that enrolled periprosthetic joint infection cases associated with total knee arthroplasty managed with a two-stage exchange protocol have reported success rates between 72 and 95\% [4348] Some systematic reviews have reported a higher success rate with two-stage exchange in the eradication

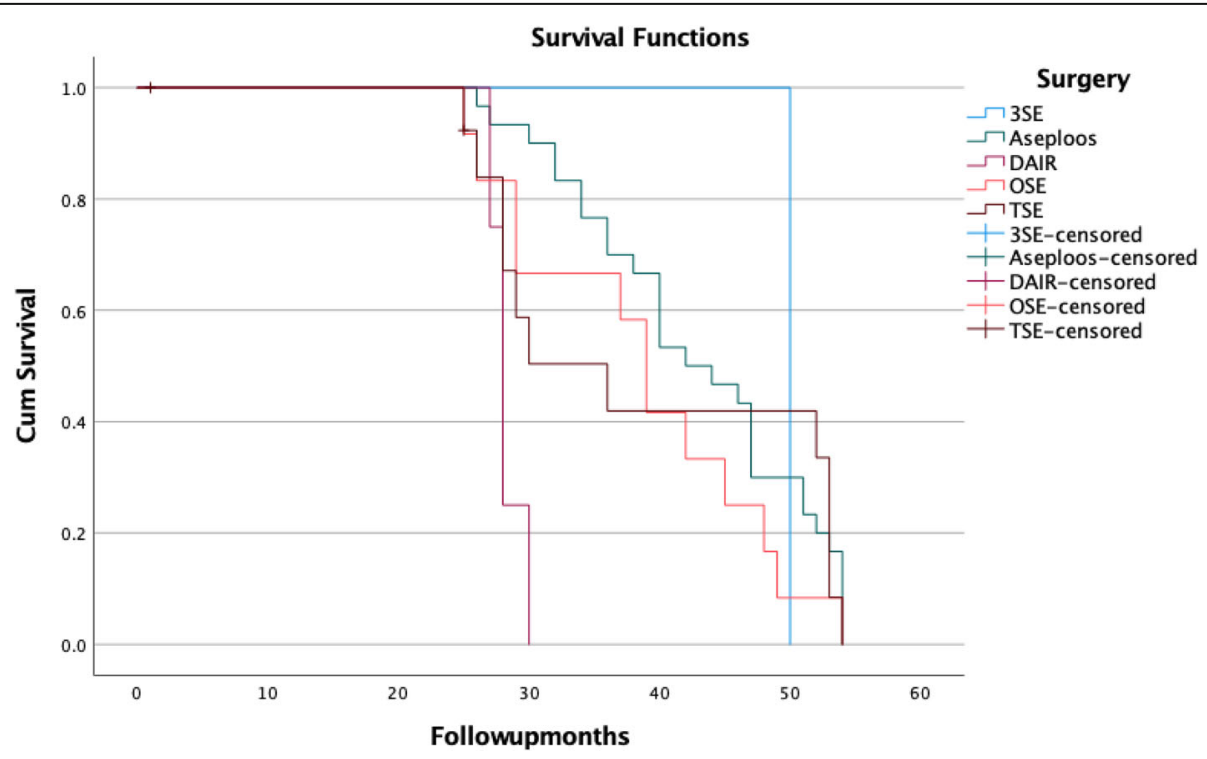

Fig. 3 Kaplan-Meier survival plot of the study group by type of surgical procedure 
Table 3 Kaplan-Meier survival index by procedure, and date

\begin{tabular}{lll}
\hline Surgery & Time (months) & Kaplan-Meier Survival at the Time \\
\hline 3SE & 12 & $100.00 \%$ \\
& 25 & $100.00 \%$ \\
TSE & 12 & $100.00 \%$ \\
& 25 & $92.30 \%$ \\
OSE & 12 & $100.00 \%$ \\
DAIR & 25 & $91.70 \%$ \\
& 12 & $100.00 \%$ \\
Aseptic loosening intervention & 25 & $75.00 \%$ \\
& 12 & $100.00 \%$ \\
\hline
\end{tabular}

of infection when analyzing knee periprosthetic joint infections $[49,50]$.

There is a constant debate between which is the standard for treating PJIs, some studies suggest that the twostage exchange procedure is the standard, other studies claimed that two-stage exchange procedures are complex and lead to increased morbidity and a less favorable functional result, these studies advocate for a one-stage exchange strategy [51-54]. Analyzing the type of surgical procedure implemented in our study, depending on the type of periprosthetic joint infection, and the year of enrollment of the patients, differences were observed in terms of the adopted strategy. Differences that in our opinion, most likely, occurred with the increase of the confidence level in the diagnostic and management strategies implemented through this research and with the publication, in the literature, of the long-term results obtained following the use of the same strategies in different reference centers at international level.

Second-generation lipoglycopeptide antibiotics that are used to treat acute bacterial skin and skin structure infections wight be options for difficult to treat PJIs [55]. Nasir et al. evaluated the efficacy of antibiotic combinations by calculating the fractional inhibitory concentration index (FICI) using the minimum inhibitory concentration; an FICI $\leq 0.5$ was interpreted as "synergistic". An antibiotic combination was interpreted as "synergistic" when $\geq 2-\log 10$ reduction in growth was observed in the colony forming units. The use of amoxicillin-clavulanic acid combinations with cephradine seems to be synergistic with XDR methicillinresistant $S$. aureus, and the combination with ciprofloxacin is effective against Gram-negative bacteria [56]. A constant increase of the lack of susceptibility of the isolated strain from PJIs and also the lack of new and costefficient antibiotic management strategies may encourage the development of natural treatments, there are some studies that consider it useful to use biologically active phytocomplexes instead of antibiotic therapy, consequently reducing bacterial resistance to commonly used antibiotics or of Lavender essential oils (Lavanda sumian and Lavanda grosso) that significantly reduce the nitric oxide synthase activity in a cell model [57, 58]. Different nanomaterials in biomedicine have studied for their unique properties, silver nanoparticles being one of them due to their good antibacterial activity being and alternative option in wound and bone healing. The use of a silver-containing hydroxyapatite (Ag-HA) coating in combination with vancomycin has a suppressive effect in cases of biofilm associated infections (PJIs) with methicillin-resistant Staphylococcus aureus, might being a useful strategy of the prevention of methicillinresistant Staphylococcus aureus -associated PJIs [59, 60].

Delayed and late infections are predominantly caused by low-virulent microorganisms like Coagulase-negative staphylococci and anaerobes (eg Cutibacterium species). The proportion of PJI caused by anaerobes varies from 3 up to $24 \%$. An early recognition and management of these PJIs is important, as the mortality rate is increasing and having in mind the fact that many anaerobic species have developed resistance. The use of different bacteria culture media could increase the rate of diagnosis of PJIs caused by anaerobes. Lytic (BACTEC) and SN (BacT/ ALERT) blood culture media increased the detection rate of Cutibacterium acnes [61-63].

The treatment strategy, in our opinion, should finally be selected by the surgeon, in association with the patient, and together with the input of the infectious disease specialist. Several authors and expert groups have suggested algorithms to help choose the right treatment strategy for each patient [18, 64-66].

Our study also had some limitations. First, the type of the study, a monocentric, observational, cohort study. Second, the small population of enrolled patients in the study, respectively the number of cases with periprosthetic joint infections included associated with a relatively short period of enrollment and follow-up. Third, the center where this study is conducted is not a 
dedicated center for the treatment of periprosthetic joint infections, but with the introduction of the new protocol and the dedicated team to manage these cases (orthopedic surgeon - infectious disease specialist - microbiologist), the results are encouraging. Larger studies are needed to confirm these results. However, our results are very promising.

\section{Conclusions}

Our study has good results similar to previously published data. Because of our study limitations (small number of patients and a relatively short period of followup), we cannot recommend one strategy of managing prosthetic joint infections over the other. Definitely, there is a need for prospective randomized controlled trials comparing treatment strategies to validate our data.

\section{Abbreviations}

PJl: Periprosthetic joint infections; rRNA: Ribosomal ribonucleic acid; bbFISH: beacon-based fluorescent in situ hybridization;

PMMA: Polymethylmethacrylate; 3SE: Three-stage exchange; TSE: Two-stage exchange; OSE: One-stage exchange; DAIR: Debridement and implant retention

\section{Acknowledgements}

Not applicable.

\section{Authors' contributions}

$R M B, V B$ and CRS made contribution in equal parts to this manuscript in terms of acquisition, analysis and interpretation of data, conception and design, and drafting the manuscript. RMB designed the study and coordinated data collection. VB, and RMB were involved in providing the treatment for the patients and in collecting the data. Also, MM, PM and CRS were involved in collecting the data. VB, AIF and RMB performed the statistical analysis of the data. VB, RMB, and CRS were involved in interpretation of data. MM, PM and CRS were involved in drafting the manuscript. All authors were involved in revising the manuscript. All authors read and approved the final version of the manuscript.

\section{Funding}

No funding was received by the authors.

\section{Availability of data and materials}

All data generated or analysed during this study are included in this published article and are available from the corresponding author on reasonable request.

\section{Declarations}

\section{Ethics approval and consent to participate}

The study was accepted by the Ethics Committee of the Academic Emergency Hospital Sibiu, Romania and they encouraged publishing the article (ID:8718/28-03-16). All methods were carried out in accordance with relevant guidelines and regulations. Informed consent was obtained from all subjects for study participation.

\section{Consent for publication}

Not applicable.

\section{Competing interests}

The authors have no conflicts of interest to disclose.

\section{Author details}

'Lucian Blaga University of Sibiu, Faculty of Medicine Sibiu, Str. Lucian Blaga, Nr. 2A, 550169 Sibiu, Romania. ${ }^{2}$ Lucian Blaga University of Sibiu, Bd-ul.
Victoriei, Nr.10, 550024 Sibiu, Romania. ${ }^{3}$ Carol Davila University of Medicine and Pharmacy, Bucharest, Romania. ${ }^{4}$ FOISOR Clinical Hospital of Orthopedics, Traumatology, and Osteoarticular TB Bucharest, Str. Dionisie Lupu nr. 37, Sector 2, 020021 Bucharest, Romania. ${ }^{5}$ Academic Emergency Hospital Sibiu Infectious Diseases Clinic, B-dul Corneliu Coposu, Nr.2-4, 550245 Sibiu, Romania.

Received: 21 May 2021 Accepted: 20 July 2021

Published online: 12 August 2021

\section{References}

1. Høiby N. A short history of microbial biofilms and biofilm infections. APMIS. 2017;125(4):272-5. https://doi.org/10.1111/apm.12686 PMID: 28407426.

2. Wolcott RD, Rhoads DD, Bennett ME, et al. Chronic wounds and the medical biofilm paradigm. J Wound Care. 2010;19(2):45-6. https://doi.org/1 0.12968/jowc.2010.19.2.46966 48-50, 52-3. PMID: 20216488.

3. Birlutiu RM, Birlutiu V, Cismaius RS, Mihalache P, Mihalache M. Bacterial biofilm: a mini-review of an emerging life form of bacteria. Acta Medica Transilvanica. 2017;22(4):68-71.

4. Costerton JW, Stewart PS, Greenberg EP. Bacterial biofilms: a common cause of persistent infections. Science. 1999;284(5418):1318-22. https://doi.org/1 $0.1126 /$ science. 284.5418 .1318

5. Birlutiu V, Birlutiu RM. Endocarditis due to Abiotrophia defectiva, a biofilmrelated infection associated with the presence of fixed braces: a case report. Medicine (Baltimore). 2017;96(46):e8756. https://doi.org/10.1097/MD. 0000000000008756.

6. Birlutiu V, Birlutiu RM, Costache VS. Viridans streptococcal infective endocarditis associated with fixed orthodontic appliance managed surgically by mitral valve plasty: a case report. Medicine (Baltimore). 2018; 97(27):e11260. https://doi.org/10.1097/MD.0000000000011260.

7. Sahuquillo-Arce $J M$, Selva M, Perpinan $H$, et al. Antimicrobial resistance in more than 100000 Escherichia coli isolates according to culture site and patient age, gender, and location. Antimicrob Agents Chemother. 2011; 55(3):1222-8. https://doi.org/10.1128/AAC.00765-10.

8. Senobar Tahaei SA, Stájer A, Barrak I, Ostorházi E, Szabó D, Gajdács M. Correlation between Biofilm-Formation and the Antibiotic Resistant Phenotype in Staphylococcus aureus Isolates: A laboratory-based study in Hungary and a review of the Literature. Infect Drug Resist. 2021;14:1155-68. https://doi.org/10.2147/IDR.S303992 PMID: 33790586; PMCID: PMC8001189.

9. Behzadi P, Urbán E, Gajdács M. Association between Biofilm-Production and Antibiotic Resistance in Uropathogenic Escherichia coli (UPEC): An In Vitro Study. Diseases. 2020;8(2):17. https://doi.org/10.3390/diseases8020017 PMID: 32517335; PMCID: PMC7348726.

10. Birlutiu RM, Birlutiu V, Mihalache M, Mihalache C, Cismasiu RS. Diagnosis and management of orthopedic implant-associated infection: a comprehensive review of the literature. Biomed Res. 2017:28:5063-73.

11. Fischbacher $A$, Borens $O$. Prosthetic-joint infections: mortality over the last 10 years. J Bone Joint Infect. 2019;4(4):198-202. https://doi.org/10.7150/jbji.3 5428.

12. Natsuhara KM, Shelton TJ, Meehan JP, Lum ZC. Mortality during total hip periprosthetic joint infection. J Arthroplast. 2019;34(7):S337-42. https://doi. org/10.1016/j.arth.2018.12.024.

13. Wang FD, Wang YP, Chen CF, Chen HP. The incidence rate, trend and microbiological aetiology of prosthetic joint infection after total knee arthroplasty: a 13 years' experience from a tertiary medical center in Taiwan. J Microbiol Immunol Infect. 2018:51(6):717-22. https://doi.org/10.1016/j. jmii.2018.08.011.

14. Boddapati V, Fu MC, Mayman DJ, Su EP, Sculco PK, MCLawhorn AS. Revision total knee arthroplasty for periprosthetic joint infection is associated with increased postoperative morbidity and mortality relative to noninfectious revisions. J Arthroplast. 2018;33(2):521-6. https://doi.org/10.1016/j.arth.2017. 09.021.

15. Birlutiu RM, Roman MD, Cismasiu RS, et al. Sonication contribution to identifying prosthetic joint infection with Ralstonia pickettii: a case report and review of the literature. BMC Musculoskelet Disord. 2017:18(1):311. https://doi.org/10.1186/s12891-017-1678-y PMID: 28724376; PMCID: PMC5518162.

16. Birlutiu RM, Birlutiu V, Cismasiu RS, Mihalache M. bbFISH-ing in the sonication fluid. Medicine. 2019:98(29):e16501. https://doi.org/10.1097/MD. 0000000000016501. 
17. Parvizi J, Zmistowski B, Berbari EF, Bauer TW, Springer BD, Della Valle CJ, et al. New definition for periprosthetic joint infection: from the workgroup of the musculoskeletal infection society. Clin Orthop Relat Res. 2011;469(11): 2992-4. https://doi.org/10.1007/s11999-011-2102-9.

18. Zimmerli W, Trampuz A, Ochsner PE. Prosthetic-joint infections. N Engl J Med. 2004;351(16):1645-54. https://doi.org/10.1056/NEJMra040181.

19. Gundtoft PH, Pedersen AB, Varnum C, Overgaard S. Increased mortality after prosthetic joint infection in primary tha. Clin Orthop Relat Res. 2017:475(11): 2623-31. https://doi.org/10.1007/s11999-017-5289-6.

20. Zmistowski B, Karam JA, Durinka JB, Casper DS, Parvizi J. Periprosthetic joint infection increases the risk of one-year mortality. J Bone Joint Surg Am. 2013;95(24):2177-84. https://doi.org/10.2106/JBJS.L.00789.

21. Miletic KG, Taylor TN, Martin ET, Vaidya R, Kaye KS. Readmissions after diagnosis of surgical site infection following knee and hip arthroplasty. Infect Control Hosp Epidemiol. 2014;35(2):152-7. https://doi.org/10.1086/674 854.

22. Husted $H$, Otte KS, Kristensen BB, Orsnes T, Kehlet $H$. Readmissions after fasttrack hip and knee arthroplasty. Arch Orthop Trauma Surg. 2010;130(9): 1185-91. https://doi.org/10.1007/s00402-010-1131-2.

23. Leta TH, Lygre SHL, Schrama JC, Hallan G, Gjertsen JE, Dale H, et al. Outcome of revision surgery for infection after Total knee arthroplasty: results of 3 surgical strategies. JBJS Rev. 2019;7(6):e4. https://doi.org/10.2106/ JBJS.RWW.18.00084

24. Masters JP, Smith NA, Foguet P, Reed M, Parsons H, Sprowson AP. A systematic review of the evidence for single stage and two stag revision of infected knee replacement. BMC Musculoskelet Disord. 2013;14:222.

25. Kunutsor SK, Whitehouse MR, Lenguerrand E, Blom AW, Beswick AD, Team I. Re-infection outcomes following 1- and 2-stage surgical revision of infected knee prosthesis: a systematic review and meta-analysis. PLoS One. 2016; 11(3):e0151537. https://doi.org/10.1371/journal.pone.0151537.

26. Nagra NS, Hamilton TW, Ganatra S, Murray DW, Pandit H. One-stage versus two-stage exchange arthroplasty for infected total knee arthroplasty: a systematic review. Knee Surg Sports Traumatol Arthrosc. 2016;24(10):310614. https://doi.org/10.1007/s00167-015-3780-8.

27. Konigsberg BS, Della Valle CJ, Ting NT, Qiu F, Sporer SM. Acute hematogenous infection following total hip and knee arthroplasty. Arthroplast. 2014;29(3):469-72. https://doi.org/10.1016/j.arth.2013.07.021.

28. Cobo J, Miquel LG, Euba G, Rodríguez D, García-Lechuz JM, et al. Early prosthetic joint infection: outcomes with debridement and implant retention followed by antibiotic therapy. Clin Microbiol Infect. 2011;17(11): 1632-7. https://doi.org/10.1111/j.1469-0691.2010.03333.x Epub 2010 Jul 30. PMID: 20678178.

29. Marculescu CE, Cantey JR. Polymicrobial prosthetic joint infections: risk factors and outcome. Clin Orthop Relat Res. 2008;466(6):1397-404. https:// doi.org/10.1007/s11999-008-0230-7.

30. Soriano A, García S, Bori G, Almela M, Gallart X, Macule F, et al. Treatment of acute post-surgical infection of joint arthroplasty. Clin Microbiol Infect. 2006: 12(9):930-3. https://doi.org/10.1111/j.1469-0691.2006.01463.x.

31. Westberg M, Grøgaard B, Snorrason F. Early prosthetic joint infections treated with debridement and implant retention: 38 primary hip arthroplasties prospectively recorded and followed for median 4 years. Acta Orthop. 2012;83(3):227-32. https://doi.org/10.3109/17453674.2012.678801.

32. Azzam KA, Seeley M, Ghanem E, Austin MS, Purtill JJ, Parvizi J. Irrigation and debridement in the management of prosthetic joint infection: traditional indications revisited. J Arthroplast. 2010;25(7):1022-7. https://doi.org/10.101 6/j.arth.2010.01.104.

33. Odum SM, Fehring TK, Lombardi AV, Zmistowski BM, Brown NM, Luna JT, et al. Periprosthetic infection consortium. Irrigation and debridement for periprosthetic infections: does the organism matter? J Arthroplast. 2011;26(6 Suppl):114-8. https://doi.org/10.1016/j.arth.2011.03.031.

34. Sukeik M, Patel S, Haddad FS. Aggressive early débridement for treatment of acutely infected cemented total hip arthroplasty. Clin Orthop Relat Res. 2012:470(11):3164-70. https://doi.org/10.1007/s11999-012-2500-7.

35. Buchholz HW, Elson RA, Engelbrecht E, Lodenkämper H, Röttger J, Siegel A. Management of deep infection of total hip replacement. J Bone Joint Surg Br. 1981;63-B(3):342-53. https://doi.org/10.1302/0301-620X.63B3.7021561.

36. Raut W, Siney PD, Wroblewski BM. One-stage revision of total hip arthroplasty for deep infection. Long-term followup. Clin Orthop Relat Res. 1995;321:202-7.

37. Klouche S, Leonard P, Zeller V, Lhotellier L, Graff W, Leclerc P, et al. Infected total hip arthroplasty revision: one- or two-stage procedure? Orthop
Traumatol Surg Res. 2012;98(2):144-50. https://doi.org/10.1016/j.otsr.2011.08. 018.

38. Raut W, Orth MS, Orth MC, Siney PD, Wroblewski BM. One stage revision arthroplasty of the hip for deep gram negative infection. Int Orthop. 1996; 20(1):12-4. https://doi.org/10.1007/s002640050019.

39. Engesæter LB, Dale H, Schrama JC, Hallan G, Lie SA. Surgical procedures in the treatment of 784 infected THAs reported to the Norwegian arthroplasty register. Acta Orthop. 2011;82(5):530-7. https://doi.org/10.3109/17453674.2 011.623572

40. Stockley I, Mockford BJ, Hoad-Reddick A, Norman P. The use of two-stage exchange arthroplasty with depot antibiotics in the absence of long-term antibiotic therapy in infected total hip replacement. J Bone Joint Surg Br. 2008;90(2):145-8. https://doi.org/10.1302/0301-620X.90B2.19855 PMID: 18256078 .

41. Fleck EE, Spangehl MJ, Rapuri VR, Beauchamp CP. An articulating antibiotic spacer controls infection and improves pain and function in a degenerative septic hip. Clin Orthop Relat Res. 2011;469(11):3055-64. https://doi.org/10.1 007/s11999-011-1903-1.

42. McKenna PB, O'Shea K, Masterson EL. Two-stage revision of infected hip arthroplasty using a shortened post-operative course of antibiotics. Arch Orthop Trauma Surg. 2009;129(4):489-94. https://doi.org/10.1007/s00402008-0683-x Epub 2008 Aug 2. PMID: 18677498

43. Silvestre A, Almeida F, Renovell P, Morante E, López R. Revision of infected total knee arthroplasty: two-stage reimplantation using an antibioticimpregnated static spacer. Clin Orthop Surg. 2013;5(3):180-7. https://doi. org/10.4055/cios.2013.5.3.180 Epub 2013 Aug 20. PMID: 24009903; PMCID: PMC3758987.

44. Mortazavi SM, Vegari D, Ho A, Zmistowski B, Parvizi J. Two-stage exchange arthroplasty for infected total knee arthroplasty: predictors of failure. Clin Orthop Relat Res. 2011;469(11):3049-54. https://doi.org/10.1007/s11999011-2030-8

45. Hanssen AD, Rand JA, Osmon DR. Treatment of the infected total knee arthroplasty with insertion of another prosthesis. The effect of antibioticimpregnated bone cement. Clin Orthop Relat Res. 1994;309:44-55 7994976.

46. Goldman RT, Scuderi GR, Insall JN. 2-stage reimplantation for infected total knee replacement. Clin Orthop Relat Res. 1996:331:118-24. https://doi.org/1 0.1097/00003086-199610000-00016 PMID: 8895627.

47. Haleem AA, Berry DJ, Hanssen AD. Mid-term to long-term followup of twostage reimplantation for infected total knee arthroplasty. Clin Orthop Relat Res. 2004;428:35-9. https://doi.org/10.1097/01.blo.0000147713.64235.73 PMID: 15534516.

48. Kubista B, Hartzler RU, Wood CM, Osmon DR, Hanssen AD, Lewallen DG. Reinfection after two-stage revision for periprosthetic infection of total knee arthroplasty. Int Orthop. 2012;36(1):65-71. https://doi.org/10.1007/s00264011-1267-x.

49. Jamsen E, Stogiannidis I, Malmivaara A, Pajamaki J, Puolakka T, Konttinen YT. Outcome of prosthesis exchange for infected knee arthroplasty: the effect of treatment approach. Acta Orthop. 2009;80(1):67-77. https://doi.org/10.1 080/17453670902805064.

50. Clement ND, Burnett R, Breusch SJ. Should single- or two-stage revision surgery be used for the management of an infected total knee replacement? A critical review of the literature. OA Orthopaedics. 2013;1(1): 2.

51. Fink B. Revision of late periprosthetic infections of total hip endoprostheses: pros and cons of different concepts. Int J Med Sci. 2009;6(5):287-95. https:// doi.org/10.7150/ijms.6.287.

52. Parkinson RW, Kay PR, Rawal A. A case for one-stage revision in infected total knee arthroplasty? Knee. 2011;18(1):1-4. Epub 2010 Aug 17. https://doi. org/10.1016/j.knee.2010.04.008.

53. Mortazavi SM, Schwartzenberger J, Austin MS, Purtill JJ, Parvizi J. Revision total knee arthroplasty infection: incidence and predictors. Clin Orthop Relat Res. 2010;468(8):2052-9. https://doi.org/10.1007/s11999-010-1308-6.

54. Vaishya R, Agarwal AK, Rawat SK, Singh H, Vijay V. Is single-stage revision safe following infected total knee arthroplasty? A critical review. Cureus. 2017;9(8):e1629. https://doi.org/10.7759/cureus.1629.

55. Fiore V, De Vito A, Aloisio A, Donadu MG, Usai D, Zanetti S, et al. Dalbavancin two dose regimen for the treatment of prosthetic joint infections: new possible options for difficult to treat infectious diseases. Infect Dis. 2021;53(6):473-5.

56. Nasir S, Vohra MS, Gul D, Swaiba UE, Aleem M, Mehmood K, et al. Novel antibiotic combinations of diverse subclasses for effective suppression of 
extensively drug-resistant methicillin-resistant Staphylococcus aureus (MRSA). Int J Microbiol. 2020. https://doi.org/10.1155/2020/8831322.

57. Amorese V, Donadu M, Usai D, Sanna A, Milia F, Pisanu F, et al. In vitro activity of essential oils against Pseudomonas aeruginosa isolated from infected hip implants. J Infect Dev Ctries. 2018;12(11):996-1001. https://doi. org/10.3855/jidc.10988.

58. Donadu M, Usai D, Pinna A, Porcu T, Mazzarello V, Fiamma M, et al. In vitro activity of hybrid lavender essential oils against multidrug resistant strains of Pseudomonas aeruginosa. J Infect Dev Ctries. 2018;12(1):9-14. https://doi. org/10.3855/jidc.9920.

59. Hashimoto A, Miyamoto H, Kii S, Kobatake T, Shobuike T, Noda I, et al. Timedependent efficacy of combination of silver-containing hydroxyapatite coating and vancomycin on methicillin-resistant Staphylococcus aureus biofilm formation in vitro. BMC Res Notes. 2021;14(1):81. https://doi.org/1 0.1186/s13104-021-05499-7.

60. Xu L, Wang YY, Huang J, Chen CY, Wang ZX, Xie H. Silver nanoparticles: synthesis, medical applications and biosafety. Theranostics. 2020;10(20): 8996-9031. https://doi.org/10.7150/thno.45413.

61. Tande AJ, Patel R. Prosthetic joint infection. Clin Microbiol Rev. 2014;27(2): 302-45. https://doi.org/10.1128/CMR.00111-13.

62. Gajdács M, Urbán E. Relevance of anaerobic bacteremia in adult patients: a never-ending story? Eur J Microbiol Immunol. 2020;10(2):64-75. https://doi. org/10.1556/1886.2020.00009.

63. Jeverica S, El Sayed F, Čamernik P, Kocjančič B, Sluga B, Rottman M, et al. Growth detection of Cutibacterium acnes from orthopaedic implantassociated infections in anaerobic bottles from BACTEC and BacT/ALERT blood culture systems and comparison with conventional culture media. Anaerobe. 2020;61:102133. https://doi.org/10.1016/..anaerobe.2019.102133.

64. Osmon DR, Berbari EF, Berendt AR, Lew D, Zimmerli W, Steckelberg JM, et al. Infectious Diseases Society of America. Diagnosis and management of prosthetic joint infection: clinical practice guidelines by the Infectious Diseases Society of America. Clin Infect Dis. 2013;56(1):e1-e25. https://doi. org/10.1093/cid/cis803 Epub 2012 Dec 6. PMID: 23223583.

65. Leone $\mathrm{S}$, Borrè S, Monforte AD, Mordente G, Petrosillo N, Signore A, et al. Consensus document on controversial issues in the diagnosis and treatment of prosthetic joint infections. Int J Infect Dis. 2010;14(Suppl 4): S67-77. https://doi.org/10.1016/j.jijd.2010.05.005 Epub 2010 Sep 16. PMID: 20843721.

66. Moran E, Byren I, Atkins BL. The diagnosis and management of prosthetic joint infections. J Antimicrob Chemother. 2010;65(Suppl 3):iii45-54. https:// doi.org/10.1093/jac/dkq305 PMID: 20876628

\section{Publisher's Note}

Springer Nature remains neutral with regard to jurisdictional claims in published maps and institutional affiliations.

Ready to submit your research? Choose BMC and benefit from:

- fast, convenient online submission

- thorough peer review by experienced researchers in your field

- rapid publication on acceptance

- support for research data, including large and complex data types

- gold Open Access which fosters wider collaboration and increased citations

- maximum visibility for your research: over $100 \mathrm{M}$ website views per year

At $\mathrm{BMC}$, research is always in progress.

Learn more biomedcentral.com/submissions 